\title{
ORIGINAL ARTICLE \\ Allocation to male vs female floral function varies by currency and responds differentially to density and moisture stress
}

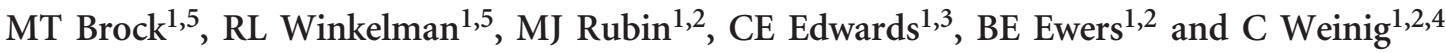

Allocation of finite resources to separate reproductive functions is predicted to vary across environments and affect fitness. Biomass is the most commonly measured allocation currency; however, in comparison with nutrients it may be less limited and express different environmental and evolutionary responses. Here, we measured carbon, nitrogen, phosphorus, and biomass allocation among floral whorls in recombinant inbred lines of Brassica rapa in multiple environments to characterize the genetic architecture of floral allocation, including its sensitivity to environmental heterogeneity and to choice of currency. Mass, carbon, and nitrogen allocation to female whorls (pistils and sepals) decreased under high density, whereas nitrogen allocation to male organs (stamens) decreased under drought. Phosphorus allocation decreased by half in pistils under drought, while stamen phosphorus was unaffected by environment. While the contents of each currency were positively correlated among whorls, selection to improve fitness through female (or male) function typically favored increased allocation to pistils (or stamens) but decreased allocation to other whorls. Finally, genomic regions underlying correlations among allocation metrics were mapped, and loci related to nitrogen uptake and floral organ development were located within mapped quantitative trait loci. Our candidate gene identification suggests that nutrient uptake may be a limiting step in maintaining male allocation. Taken together, allocation to male vs female function is sensitive to distinct environmental stresses, and the choice of currency affects the interpretation of floral allocation responses to the environment. Further, genetic correlations may counter the evolution of allocation patterns that optimize fitness through female or male function.

Heredity (2017) 119, 349-359; doi:10.1038/hdy.2017.41; published online 2 August 2017

\section{INTRODUCTION}

Allocation of limited resources is commonly expected to involve tradeoffs between competing functions, including between life-history traits (Geber, 1990; Stearns, 1992), between alternative plant responses to herbivory (Fineblum and Rausher, 1995; but see Leimu and Koricheva, 2006), and in competitive responses (Maliakal et al., 1999; Weinig, 2000a). For reproductive traits in cosexual plant species, male and female functions are expected to compete for a finite pool of resources, but studies of reproductive allocation have shown positive genotypic correlations between the absolute mass of organs serving male vs female function (Campbell, 1997) and among the sizes of floral organs (Conner and Via, 1993; Juenger et al., 2005; Brock et al., 2010). Negative correlations indicative of allocation tradeoffs may not be observed if the measured allocation currency is not limiting or, alternatively, if genotypic differences exist in resource acquisition, because genotypes with higher resource acquisition have larger resource pools and allocate comparatively more to multiple functions simultaneously than do smaller plants (van Noordwijk and Dejong, 1986; Stearns, 1992; Roff and Fairbairn, 2007; Latta and Gardner, 2009; Haselhorst et al., 2011). The evolutionary relevance of observed genetic and/or quantitative trait loci (QTL) correlations is, however, best understood in light of selection. Either negative or positive correlations could impose constraints on adaptive evolution if trait covariation is antagonistic to the joint vector of selection acting on trait pairs (Etterson and Shaw, 2001), for instance, if selection favors an increase in one trait in combination with a decrease in a second positively correlated trait.

In cosexual plant species, flowers serve both male and female functions, and preferential allocation to one gender function over the other may be favored by selection (Charlesworth and Charlesworth, 1981; Lloyd and Bawa, 1984; Lloyd, 1984; Brunet, 1992; Torices and Mendez, 2014). More specifically, angiosperms have complex reproductive structures, such that the relative contribution of each floral whorl to male vs female function must be considered in order to determine the fitness consequences of allocation to individual whorls and of correlations between whorls. In species with hermaphroditic flowers, the ovary of the pistil performs the primary female function of ovule production, while sepals fix carbon and help offset the carbon cost of seed production in at least some species, thereby serving as accessory female organs (Bazzaz et al., 1979; Galen, 1989; Laporte and Delph, 1996). Stamens are the primary male organ, producing pollen, while petals often serve in pollinator attraction, which more strongly

\footnotetext{
${ }^{1}$ Department of Botany, University of Wyoming, Laramie, WY, USA; ${ }^{2}$ Program in Ecology, University of Wyoming, Laramie, WY, USA; ${ }^{3}$ Center for Conservation and Sustainable Development, Missouri Botanical Garden, St Louis, MO, USA and ${ }^{4}$ Department of Molecular Biology, University of Wyoming, Laramie, WY, USA Correspondence: Dr C Weinig, Department of Botany or Department of Molecular Biology, University of Wyoming, Laramie, WY 82071, USA. E-mail: cweinig@uwyo.edu

5These authors contributed equally to this work.

Received 18 November 2016; revised 30 May 2017; accepted 31 May 2017; published online 2 August 2017
} 
contributes to fitness through male function in outcrossing species (Stanton et al., 1986; Li et al., 2011). Specifically, a small number of pollinator visits may enable fertilization of all ovules while additional visits improve pollen dispersal, and the attractive role of petals thus contributes disproportionately to male function (Bell, 1985; de Craene, 2003); in self-compatible species that autonomously self-pollinate, genotypes that allocate to petals may experience only an allocation cost without experiencing any improvement in fitness. We hypothesize that increased allocation of resources to primary reproductive organs will increase offspring number or quality and thus experience positive selection regardless of mating system, but that resource allocation to accessory organs such as petals will experience negative selection in self-compatible genotypes.

Apparent allocation strategies and their fitness consequences may also vary depending on the currency measured. Mass is the currency used most commonly to estimate allocation to organs in different floral whorls (Hickman and Pitelka, 1975; Abrahamson and Caswell, 1982; Reekie and Bazzaz, 1987a,b; Sakai et al., 2013; Torices and Mendez, 2014). Yet, mass may be neither limiting nor show patterns of allocation similar to other currencies (for example, N, P or K) that affect organ function and ultimately fitness (Harper, 1977; Thompson and Stewart, 1981; Chapin, 1989). A small number of previous studies suggests that mass does not predict the content (absolute amount) of other currencies in sexually dimorphic species (Lovett Doust and Harper, 1980; Ashman and Baker, 1992; Ashman, 1994a, b) or in species with hermaphroditic flowers (Mendez and Traveset, 2003; Torices and Mendez, 2014). Mass may also not reflect the concentration or proportional allocation of $\mathrm{C}, \mathrm{N}$ or $\mathrm{P}$ (where concentration is defined as the amount of a currency such as $\mathrm{N}$ in an organ divided by the mass of the organ, and proportion is defined as the amount of a currency such as $\mathrm{N}$ in an organ divided by total $\mathrm{N}$ in the flower). Increased allocation of mass with a constant allocation of a particular nutrient to an organ will result in a lower concentration of the nutrient due to dilution. Because dilution leads to lower biochemical activity, concentration and proportion may be strongly linked to performance and fitness. Despite the recognition that choice of currency and metrics (content, concentration or proportion) affect the estimation of allocation, no studies have jointly characterized both the quantitative genetic architecture of floral allocation (including QTL and candidate loci) as well as selection acting through multiple currencies.

Allocation patterns are likely to vary across environments, because environmental heterogeneity can affect the availability of and relationships among nutrients. Plasticity of reproductive allocation in response to soil nutrients has accordingly been identified in several species (Vasek et al., 1987; Havens et al., 1995; Dorken and Barrett, 2004). While soil nutrient levels directly affect the available nutrient pool, water availability and plant competition indirectly affect soil nutrient uptake by affecting photosynthesis, allocation to roots and bulk flow to roots (Maliakal et al., 1999; Weinig, 2000b; Osone et al., 2008). Plants exposed to drought conditions, for instance, have reduced carbon assimilation relative to well-watered plants because of reduced transpiration rates, which limit $\mathrm{CO}_{2}$ uptake (Schulze, 1986; Flexas et al., 2004). In cases of both drought and competition, carbon limitation may reduce plant uptake of $\mathrm{N}$ or P from the soil (Linder, 1987; Onillon et al., 1995; Welander and Ottosson, 2000), potentially leading to parallel environmental effects on reproductive allocation of biomass and nutrients. Alternatively, biomass and nutrient levels may be decoupled if $\mathrm{N}$ and $\mathrm{P}$ acquisition depends more on factors like bulk moisture flow to roots rather than the $\mathrm{C}$ budget. In sum, whether specific environmental stresses elicit parallel or divergent allocation responses of biomass vs nutrients to whorls serving female vs male function remains largely unknown.

Here, we examine the genetic architecture of reproductive allocation patterns in a segregating progeny of the hermaphroditic species, Brassica rapa. We measure four currencies within each floral whorl in three environments to estimate allocation. As part of statistical genetic analyses of trait associations, we use genome-wide scans to identify QTL affecting a trait(s), and we link QTL to the physical map to identify positional candidate genes that could contribute to or constrain adaptive evolution. We address the following questions: (1) does competitive environment or moisture level affect allocation among the four floral whorls, and if so, do floral organs serving male vs female function respond similarly to the environment? (2) Is there genetic variation for $\mathrm{C}, \mathrm{N}, \mathrm{P}(\mathrm{CNP})$ or biomass allocation in the four floral organs of $B$. rapa flowers, and does allocation of one currency such as mass reflect allocation of a second currency such as CNP across environments and genotypes? (3) Is allocation to specific floral whorls associated with fitness through male and female function, and are trait correlations reinforcing or antagonistic to selection? and (4) what is the QTL architecture of floral allocation traits, and do strong candidate loci exist for floral allocation?

\section{MATERIALS AND METHODS}

\section{Study system}

Brassica rapa, a member of the mustard family (Brassicaceae), is native to temperate areas of Eurasia. The species is agronomically important, and is cultivated as leaf (spp. pekinensis, chinensis), below-ground storage (spp. rapa) and oilseed crops (spp. oleifera; Zhao et al., 2005). Recombinant inbred lines (RILs) were created by first crossing two self-compatible B. rapa genotypes, IMB211 and R500 (Iniguez-Luy et al., 2009), then selfing the resulting F1, and advancing the F2 through 8 generations of selfing and single-seed descent. IMB211 derives from the base Wisconsin fast-plant population, a rapid-cycling population produced from 10 generations of selection for early flowering and rapid generation time (Williams and Hill, 1986). R500 is a yellow Sarson genotype, with a history of cultivation in India (Hinata and Prakash, 1984). In comparison to IMB211, R500 delays reproduction, has larger flowers, and has higher reproductive output as a consequence of its larger size (Brock et al., 2010). Variation in allocation patterns segregating in this population may resemble that expected in natural populations following crop-wild hybridization (Adler et al., 1993). In natural populations, trait associations may arise in part from pleiotropy or from selection for optimal allocation, the latter of which can lead to statistical linkage disequilibrium among chromosomes or genome-wide. Because this is an experimental segregating progeny, trait associations arise from pleiotropy or from physical linkage between causal loci affecting two traits (while genome-wide linkage disequilibrium is disrupted by recombination when the experimental population is created).

\section{Experimental design}

In a field experiment, we explored the effects of plant competition and water availability on resource allocation within the RILs. In June 2010, we planted 18 replicates of each of the two parental lines and 126 of the RILs in peat pots $(9 \times 9 \times 10 \mathrm{~cm})$ filled with field soil from the Agricultural Experiment Station (AES) in Laramie, WY. Six replicates per genotype were randomly assigned to each of three treatments: non-competitive/well-watered (control), competitive/ well-watered (CR) and non-competitive/water-limited (DR), where the control provides a basis for comparison and determining the effects of crowding or water-limitation on allocation.

For the non-competitive treatments, seeds were planted centrally in each pot. In the competitive treatment, the central seeds were surrounded by four sets of genetically identical neighboring seeds each planted $1 \mathrm{~cm}$ from the central position. During germination and seedling establishment, flats were placed in the AES greenhouse. A week after germination, pots were thinned to one or five seedlings in non-competitive and competitive treatments, respectively. Plants 
were watered daily, and the temperature in the greenhouse was kept as close to ambient temperature as possible with a night time minimum threshold of $8{ }^{\circ} \mathrm{C}$.

Fifteen days after germination plants were transplanted to experimental blocks in a field site adjacent to the greenhouse. Genotypic replicates were fully randomized into blocks in a split-plot design of competitive or non-competitive treatments, with replicates positioned $\sim 25 \mathrm{~cm}$ apart. Well-watered treatments (CR and control) were irrigated to field capacity each morning. Water-limited blocks (DR) were checked with a soil-moisture probe (10-HS; Decagon Devices, Pullman, WA, USA) each afternoon, and were watered when the soil moisture level was below $8 \%$ on average in 30 measurements taken at random across several blocks. Soil measurements averaged $17.5 \%$ volumetric water content across well-watered blocks and 6.5\% volumetric water content across water-limited blocks, a level low enough to reduce fruit set by $48 \%$ relative to the well-watered treatment.

\section{Sample collection and elemental analyses}

To determine whether the RILs exhibited genetic variation in mass and in CNP allocation, we first analyzed the allocation patterns of 18 RILs expressing a range of variation in floral size based on earlier studies (Brock et al., 2010); we initially focused on a subset of RILs to minimize floral processing time and the cost of nutrient analyses, and to guide the selection of one environment for analysis of all RILs. Buds were collected from all replicates of the 18 genotypes within each of the three treatments. One day after a plant started flowering, the two largest buds (that is, buds with stamens and pistils in final stages of maturation and likely to open the following day; see Zhang et al., 2016; Figure 2, p2-p3 images for similar floral stage in Brassica napus) were collected. Buds were dissected (into the pistil, stamens, petals and sepals), dried at $65^{\circ} \mathrm{C}$ overnight, and then weighed to the nearest $0.0001 \mathrm{mg}$ using a SE2 ultramicrobalance (Sartorius, Goettingen, Germany).

Nitrogen and carbon content were measured for each floral organ for all replicates of the 18 RILs in each of the three treatments at the University of Wyoming Stable Isotope Facility using an EA1108 Element Analyzer (Costech, Valencia, California). Phosphorus was quantified in these samples using a standard ammonium molybdate blue ascorbic acid method (Chen et al., 1956). Because RIL responses to treatment were similar (see Results) and to limit the costs of elemental nutrient analysis, floral parts from the same whorl were pooled from replicates of each of the remaining 108 RILs planted in the control treatment, thus providing genotypic values.

\section{Selection on floral currencies through male or female fitness}

We evaluated selection through male and female function on resource allocation to floral organs. To estimate total male fitness across all RILs, we counted the number of phenotypically normal anthers per flower, collected a single undehisced long anther to quantify pollen production, and determined pollen viability of newly dehisced long anthers. Brassicaceous flowers have 6 stamens, and these may vary in success of formation (Supplementary Information,Supplementary Figure S1). To quantify anther production, we counted the number of phenotypically normal anthers from a single flower on up to 6 replicates of each RIL. We then harvested undehisced anthers of newly opening flowers (0800-0900 h) from three replicates of each RIL and quantified the number of pollen grains from each anther using a Millipore Scepter coulter counter with $60 \mu \mathrm{m}$ sensor (Millipore, Billerica, MA, USA). Finally, we quantified pollen viability from up to 4 replicates of each RIL by harvesting a dehisced anther (1100-1200 h), staining pollen with MTT (Rodriguez-Riano and Dafni, 2000), which colors viable pollen a deep pink color, and visually inspecting color in 100 grains to estimate percent viability. Flowers (or anthers) used to phenotype anther production and pollen production and quality were sampled from the primary stem from each replicate plant two days after first flower production; the first two flowers were excluded to avoid possible developmental instability commonly observed among the first flowers (Diggle, 1997). Using genotypic values, we estimated male performance on a per flower basis as average viable pollen production: proportion normal anthers $\times$ pollen production $\times$ percent pollen viability. To quantify selection through male function, we estimated total male fitness at the whole-plant level as: pollen production per flower $\times$ flower number.
As components of female performance per flower, we estimated the average number of seeds from four fruit collected from the primary stem, and counted the total number of fruit produced by each replicate plant. We estimated fitness through female function as total seed set of each plant as: average seed per fruit $\times$ total number of fruit.

\section{Statistical analysis}

Environmental sensitivity of and genetic variation in floral allocation. We tested for differences in floral allocation in the subset of 18 RILs. In analysis of variance (ANOVA; PROC MIXED, SAS ver. 9.2), treatment was evaluated as a fixed effect, while genotype and the genotype $\times$ treatment interaction were evaluated as random effects. We tested for effects of these mixed-model factors on the mass and CNP content, concentration and proportion of each organ. The source of significant treatment effects was evaluated by post hoc Tukey's tests. For mass and $\mathrm{P}$, block nested within treatment was also tested as random effect. The block effect could not be tested for $\mathrm{N}$ and $\mathrm{C}$, because it was necessary to pool 2 replicates from different blocks for some RILs to attain a sample sufficiently large for analysis. Block was, however, non-significant in a subset of $\mathrm{N}$ and $\mathrm{C}$ data for which block was available (data not shown). The lack of block effect for some RILs suggests that microenvironmental variation had little effect on allocation, although we cannot exclude the possibility that the lack of block in the model inflated (or reduced) the effect of other factors in the model.

Analyses for genotype and treatment effects were performed at the level of both the flower and the whole-plant reproductive budget. The two sampled flowers from each replicate plant of each RIL were analyzed to obtain flowerlevel estimates of allocation; genotypic (RIL) values for the two flowers were multiplied by the total number of flowers produced to estimate the whole-plant reproductive budget.

Genotypic correlations and selection on allocation. Within the control treatment, we performed ANOVA using the entire set of 126 RILs to test for effects of block and RIL on allocation patterns and fitness traits (PROC MIXED, SAS ver. 9.2). Genotypic values (best linear unbiased predictors) generated from the preceding model were used to test for bivariate correlations (PROC CORR, SAS ver. 9.2) in resource allocation in this larger data set. To test if allocation of one currency predicts another, we tested for genotypic correlations between mass and both content, and concentration of $\mathrm{C}, \mathrm{N}$ or $\mathrm{P}$ within each floral organ. To test for possible allocation tradeoffs, we estimated associations of content and concentration of each currency between floral organs, for instance, if concentration of $\mathrm{C}(\mathrm{N}$ or $\mathrm{P})$ to stamens was correlated with allocation to other whorls. We did not use proportional allocation in this analysis, because proportions sum to 1 and an increase in proportional allocation is necessarily associated with a decrease in proportion allocated to a second function.

To explore multivariate selection on floral allocation patterns, we regressed (PROC GLM, SAS ver. 9.2) relative female fitness (estimated as total seed set) and relative male fitness (estimated as total viable pollen production) on plant biomass and genotypic values of nutrient allocation across the four floral whorls (Lande and Arnold, 1983; Rausher, 1992), again using the larger data set of 126 RILs within the control treatment. Because content showed the highest genetic variances, content and concentration of a given currency were strongly positively correlated, and the direction and commonly the significance of these multivariate relationships are similar for $\mathrm{C}, \mathrm{N}$ and $\mathrm{P}$, we present selection analyses on $\mathrm{N}$ content. Fitness measures were relativized to the population mean and floral nutrient genotypic values were standardized to a mean of zero and a s.d. of one.

QTL mapping and candidate gene analyses. We used a dense linkage map consisting of 1273 SNPs that were identified from RNAseq analyses and were mapped across the $10 \mathrm{~B}$. rapa chromosomes in the BraIRRI population (Iniguez-Luy et al., 2009; Brock et al., 2016; Markelz et al., 2017. To map QTL, we performed composite interval mapping as implemented in QTL Cartographer (ver. 2.5; Wang et al., 2007). The composite interval mapping procedure tests the hypothesis that a QTL resides in the interval defined by two adjacent markers, while statistically controlling for QTL segregating elsewhere in the genome (see Supplementary Table S1 Methods footnote for additional mapping details). 
To identify candidate genes that may underlie genetic variation in CNP allocation, we selected two well-defined QTL that regulate nutrient allocation to either stamens or pistils (without affecting allocation to other organs). We extracted genes within each of the QTL 2-LOD intervals (Brassica genome v1.5) and for each Brassica gene we determined the most likely Arabidopsis thaliana homolog. Arabidopsis gene annotations were screened for genes involved in CNP acquisition and floral organ development.

\section{RESULTS}

\section{Environmental sensitivity of and genetic variation in floral} allocation

We used mixed-model ANOVA to partition variance in mass and CNP content attributable to environment, genotype and their interaction in the subset of 18 RILs. Treatment significantly affected approximately half of the floral allocation traits (Tables 1 and 2). Post hoc contrasts testing for the source of significant treatment effects show that mass and $\mathrm{C}$ in pistils and sepals was similarly high in the control and the drought (DR) treatments, but lower in the competitive (CR) treatment (Table 2). No effect of treatment on mass was observed for stamens or petals. The results indicate that allocation of mass and $\mathrm{C}$ to the female organs is strongly affected by competition but not drought, while male organs are unaffected.

Total $\mathrm{N}$ accumulation was significantly higher in the control treatment relative to both the DR and CR treatments. N content of

Table 1 Analysis of variance in 18 RILs, partitioning of variation attributable to genotype, treatment and genotype $\times$ treatment interaction on mass and content of carbon, nitrogen and phosphorous in floral whorls

\begin{tabular}{|c|c|c|c|c|c|}
\hline \multirow[t]{2}{*}{ Trait } & \multicolumn{2}{|c|}{ Fixed effects } & \multicolumn{3}{|c|}{ Random effects } \\
\hline & $d f$ & Treatment (Trt) & Block (Trt) & Genotype & Genotype $\times$ Trt \\
\hline Pistil mass & $\mathrm{F}_{2,14}$ & $8.66^{* *}$ & 0.32 & $2.28^{*}$ & $1.49^{\dagger}$ \\
\hline Stamen mass & $\mathrm{F}_{2,20}$ & $2.87^{\dagger}$ & 0.56 & $2.48^{*}$ & $2.2^{*}$ \\
\hline Petal mass & $F_{2,19}$ & 1.32 & 1.02 & $2.05^{*}$ & $2.12^{*}$ \\
\hline Sepal mass & $F_{2,16}$ & $3.85^{* *}$ & $1.38^{\dagger}$ & $2.24^{*}$ & $1.68^{*}$ \\
\hline Total mass & $\mathrm{F}_{2,22}$ & 0.18 & 0.96 & $2.17^{*}$ & $2.41^{* *}$ \\
\hline Pistil C content & $\mathrm{F}_{2,19}$ & $6.49^{* *}$ & NA & $2.11^{*}$ & 0 \\
\hline $\begin{array}{l}\text { Stamen C } \\
\text { content }\end{array}$ & $F_{2,33}$ & 1.1 & NA & $2.04^{*}$ & $1.35^{\dagger}$ \\
\hline Petal C content & $F_{2,38}$ & 0.89 & NA & $2.26^{*}$ & 0.64 \\
\hline Sepal C content & $\mathrm{F}_{2,31}$ & $5.34^{*}$ & NA & $1.91^{*}$ & 0.24 \\
\hline Total C content & $\mathrm{F}_{2,31}$ & 1.05 & NA & $2.09 *$ & $1.31^{\dagger}$ \\
\hline Pistil N content & $\mathrm{F}_{2,19}$ & $6.74^{* *}$ & NA & $2.23^{*}$ & 0 \\
\hline $\begin{array}{l}\text { Stamen N } \\
\text { content }\end{array}$ & $\mathrm{F}_{2,35}$ & $7.89 * *$ & NA & $2.47^{* *}$ & 0.3 \\
\hline Petal N content & $\mathrm{F}_{2,19}$ & $2.57^{\dagger}$ & NA & $2.09 *$ & 0 \\
\hline Sepal N content & $\mathrm{F}_{2,18}$ & $4.93^{* *}$ & NA & $2.07^{*}$ & 0 \\
\hline Total N content & $\mathrm{F}_{2,34}$ & $4.98^{*}$ & NA & $2.31 *$ & 1.14 \\
\hline Pistil P content & $F_{2,10}$ & $7.79 * *$ & $1.6^{\dagger}$ & 0.55 & 0 \\
\hline $\begin{array}{l}\text { Stamen P } \\
\text { content }\end{array}$ & $\mathrm{F}_{2,13}$ & 0.91 & $1.77^{*}$ & $2.02 *$ & $1.61^{\dagger}$ \\
\hline Petal P content & $F_{2,10}$ & $8.28^{* *}$ & 1.14 & 1.16 & 0.3 \\
\hline Sepal P content & $\mathrm{F}_{2,14}$ & 0.62 & $2.0^{*}$ & $1.96^{*}$ & $1.89 *$ \\
\hline Total P content & $\mathrm{F}_{2,13}$ & 1.57 & $1.99 *$ & $1.54^{\dagger}$ & $1.75^{*}$ \\
\hline
\end{tabular}

the pistil and sepals was similar across the control and DR treatments, and lower in the CR treatment (Table 2). N content of the stamen was similar across the control and CR treatments, but reduced in DR Petal $\mathrm{N}$ was unaffected by treatment (mean $=0.020 \pm 0.001 \mathrm{mg}$ over all treatments). In sum, the results indicate that $\mathrm{N}$ allocation to organs serving putatively female function (pistil and sepal) is sensitive to density as is the case for mass and $\mathrm{C}$, while male (stamen) $\mathrm{N}$ allocation is sensitive to drought or environmentally insensitive (petals).

Allocation of $\mathrm{P}$ to pistils and petals was similar in the control and CR treatments, and was approximately twofold higher in these two treatments than in DR (Table 2). No effect of treatment was observed on stamen or sepal P content. Notably, the environmental effects on $\mathrm{P}$ allocation differ from mass, $\mathrm{C}$ and $\mathrm{N}$ allocation.

Treatment effects were likewise significant for concentration and proportional allocation of CNP in the majority of cases $(P<0.05$ for treatment effect in 8 out of 12 tests for concentration and 10 out of 12 for proportion), indicating that environmental effects on content of CNP are not driven solely by changes in mass of the organs (concentration) or total currency pool in the flower (proportion).

The 18 RILs differed significantly in mass, $\mathrm{C}$ and $\mathrm{N}$ content in all organs (Table 1); for P content, the effect of genotype was significant for stamens and sepals. Genotypes varied up to twofold in allocation of $\mathrm{C}, \mathrm{N}$ or $\mathrm{P}$ to any organ (Figure 1 ). genotype $\times$ treatment interaction (genotype $\times$ environment interactions) were rarely significant, except for mass of all organs and sepal P content (Table 1). Relative to the control treatment, some genotypes increased mass of individual floral organs in response to drought or competition, while others decreased allocation (Supplementary Information,Supplementary Figures S2A-D). The lack of genotype $\times$ treatment interaction for other currencies indicates that the rank order and variance among RILs was constant across treatments.

We further tested for treatment effects on allocation using the whole-plant reproductive budget, using the genotypic values from the preceding flower-level responses multiplied by the total number of flowers. Allocation to each whorl was negatively affected by both drought and competition for each currency (Supplementary Information,Supplementary Table S2), reflecting the significant reduction in flower production in these two treatments relative to the control (control: 175.8 \pm 7.5 (mean $\pm \mathrm{SE}) ; \quad \mathrm{DR}$ : 90.9 \pm 7.6 ; CR: $57.2 \pm 8.0)$.

\section{Genotypic correlations among currencies within floral whorls}

To test whether CNP and mass are equivalent currencies at the genetic level, that is, whether genotypic allocation of mass to an organ predicts allocation of other nutrients, we tested correlations between mass and the content or concentration of CNP within the control treatment where the sample size was largest ( $N=126$ RILs). Mass, not surprisingly, was positively correlated with CNP content within each floral whorl, for example, pistil mass was highly correlated with pistil CNP (average $r=0.72$, range $0.37-0.99 ; P<0.0001$ for all bivariate correlations between mass and CNP within all floral organs). Content of each currency was also positively correlated with all other currencies within each whorl; for example, pistil $\mathrm{P}$ content was positively correlated with pistil $\mathrm{N}$ and pistil C (average $r=0.67$, range: 0.36-0.99; $P<0.0001$ for all bivariate correlations between CNP within a whorl).

Mass exhibited variable correlations with CNP concentrations within a whorl. Mass was positively correlated with $\mathrm{C}$ and $\mathrm{N}$ concentration in all whorls (average $r=0.66$, range: 0.44-0.98; $P<0.0001)$. Mass in stamens and petals was, however, uncorrelated with $\mathrm{P}$ concentration in these two organs $(r=-0.13, P=0.19$; $r=-0.15, P=0.14$, respectively), while mass in pistils and sepals 
was moderately negatively correlated with $\mathrm{P}$ concentration in these two organs ( $r=-0.34, P=0.0002 ; r=-0.37, P<0.0001$, respectively), indicating that flowers with larger mass had reduced $\mathrm{P}$ concentrations in these two whorls and that there is dilution. Correlations among concentrations of CNP within a whorl were variable. Within all floral whorls, $\mathrm{C}$ concentration was positively correlated with $\mathrm{N}$ concentration (Figure 2). By contrast, $\mathrm{N}$ and $\mathrm{P}$ concentration were uncorrelated in all whorls, while $\mathrm{C}$ and $\mathrm{P}$ concentration were negatively correlated in stamens (Figure 2). The concentration of one currency, C, in an organ was therefore reliably associated with $\mathrm{N}$, but neither $\mathrm{C}$ nor $\mathrm{N}$ reliably correlated with the concentration of $\mathrm{P}$.

Table 2 Least-square means by treatment \pm 1SE for mass, carbon, nitrogen and phosphorous content (mg) in each floral whorl

\begin{tabular}{llll}
\hline Trait & \multicolumn{1}{c}{ Control } & $\begin{array}{c}\text { Low water/no } \\
\text { competition (DR) }\end{array}$ & $\begin{array}{c}\text { Well-watered/ } \\
\text { competition (CR) }\end{array}$ \\
\hline Pistil mass & $0.42 \pm 0.02^{\mathrm{a}}$ & $0.41 \pm 0.02^{\mathrm{a}}$ & $0.33 \pm 0.02^{\mathrm{b}}$ \\
Sepal mass & $0.71 \pm 0.03^{\mathrm{a}}$ & $0.71 \pm 0.03^{\mathrm{a}}$ & $0.63 \pm 0.03^{\mathrm{b}}$ \\
Pistil C & $0.20 \pm 0.01^{\mathrm{a}}$ & $0.21 \pm 0.01^{\mathrm{a}}$ & $0.17 \pm 0.100^{\mathrm{b}}$ \\
Sepal C & $0.32 \pm 0.01^{\mathrm{a}}$ & $0.34 \pm 0.01^{\mathrm{a}}$ & $0.28 \pm 0.01^{\mathrm{b}}$ \\
Pistil N & $0.028 \pm 0.001^{\mathrm{a}}$ & $0.028 \pm 0.001^{\mathrm{a}}$ & $0.024 \pm 0.001^{\mathrm{b}}$ \\
Stamen N & $0.054 \pm 0.003^{\mathrm{a}}$ & $0.045 \pm 0.003^{\mathrm{b}}$ & $0.052 \pm 0.003^{\mathrm{a}}$ \\
Sepal N & $0.046 \pm 0.002^{\mathrm{a}}$ & $0.043 \pm 0.002^{\mathrm{a}}$ & $0.040 \pm 0.002^{\mathrm{b}}$ \\
Total N & $0.148 \pm 0.005^{\mathrm{a}}$ & $0.135 \pm 0.005^{\mathrm{b}}$ & $0.136 \pm 0.005^{\mathrm{b}}$ \\
Pistil P & $0.0026 \pm 0.0003^{\mathrm{a}}$ & $0.0012 \pm 0.0003^{\mathrm{b}}$ & $0.0023 \pm 0.0003^{\mathrm{a}}$ \\
Petal P & $0.0019 \pm 0.0002^{\mathrm{a}}$ & $0.0009 \pm 0.0002^{\mathrm{b}}$ & $0.0021 \pm 0.0002^{\mathrm{a}}$ \\
\hline
\end{tabular}

Treatments include well-watered/no competition (control), low water/no competition (DR) and well-watered/high competition (CR). Superscript letters indicate significant treatment differences from post hoc Tukey's tests $(P<0.05)$.
Genotypic correlations and selection on allocation among floral whorls

We first examined how allocation of one currency to one whorl (pistils or sepals) was related to allocation to another whorl (stamens or petals). With the exception of pistil-stamen $\mathrm{P}$ concentration $(r=-0.02, \quad P=0.93)$, all correlations between male and female function were positive using content or concentration; for example, content (or concentration) of $\mathrm{N}$ in one whorl, such as pistils, was positively correlated with content (or concentration) in all other whorls, including stamens, petals and sepals (average $r=0.46$, range: $0.17-0.64 ; P<0.066$ for all pairwise correlations involving $\mathrm{C}, \mathrm{N}$ or $\mathrm{P}$ ).

Using estimates of both female and male fitness, we detected significant selection on vegetative biomass (or overall plant size) and allocation to floral whorls (Table 3). Plants with larger biomass were favored by selection through both seed and pollen production. For floral traits, selection through female function favored genotypes that allocated more to pistil and stamen whorls while reducing allocation to sepals and petals. The direction of selection gradients on female function was largely consistent across currencies (CNP and mass; see Supplementary Information,Supplementary Table S3). Thus, the major (positive) axis of trait covariation between whorls serving primary vs secondary functions is antagonistic to the joint vectors of selection through female function, which favored increased allocation to pistils and stamens in combination with decreased allocation to petals and sepals. Selection through male function consistently favored genotypes that increased allocation (for mass, $\mathrm{C}$ and $\mathrm{N}$ ) to the stamen whorl while reducing allocation to sepals. Thus, the major (positive) axis of trait covariation is antagonistic to the joint vectors of male selection, which favored increased allocation to some whorls (for
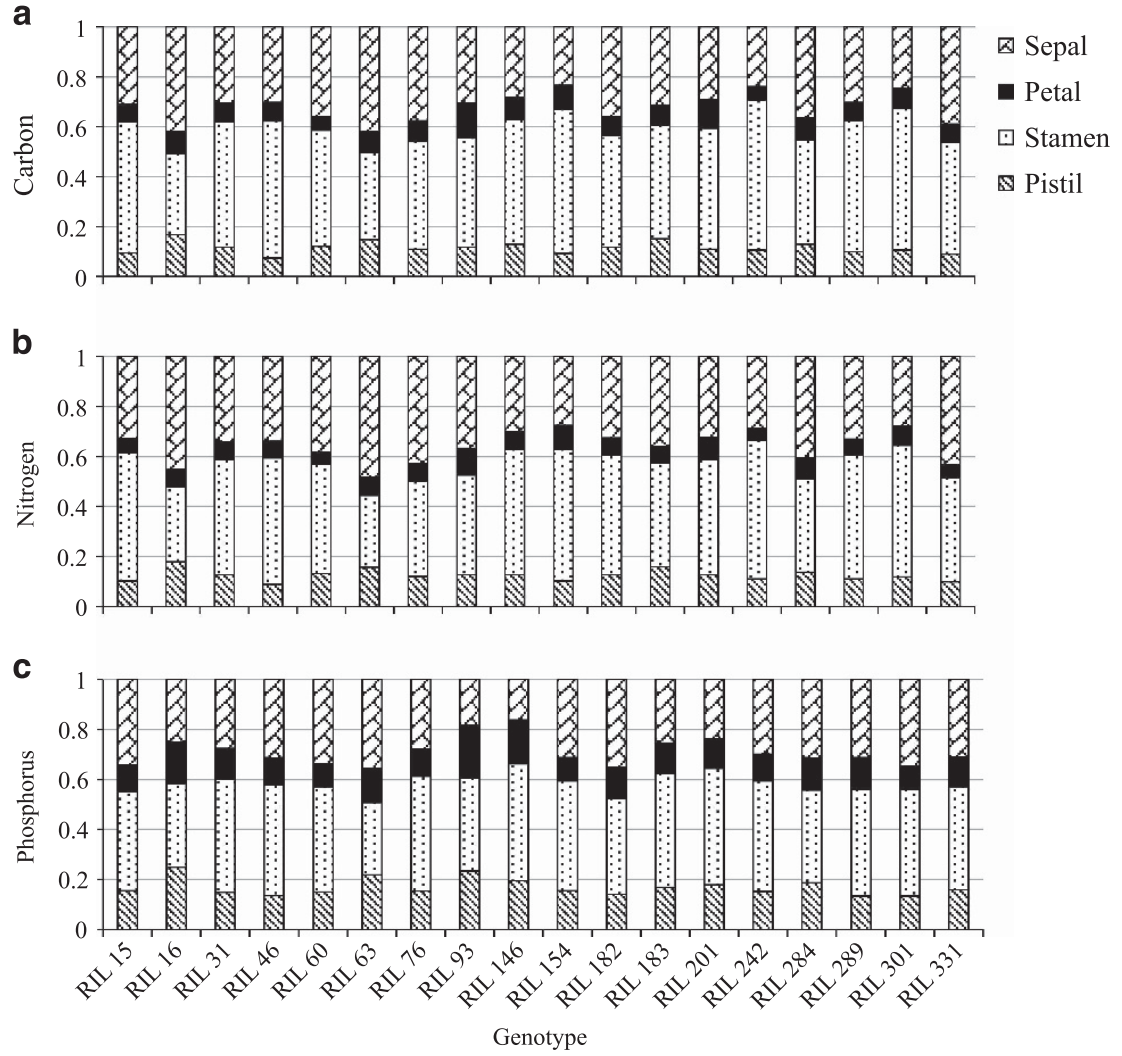

Figure 1 Proportional allocation of (a) carbon, (b) nitrogen and (c) phosphorous to individual floral organs in 18 RILs of Brassica rapa. 

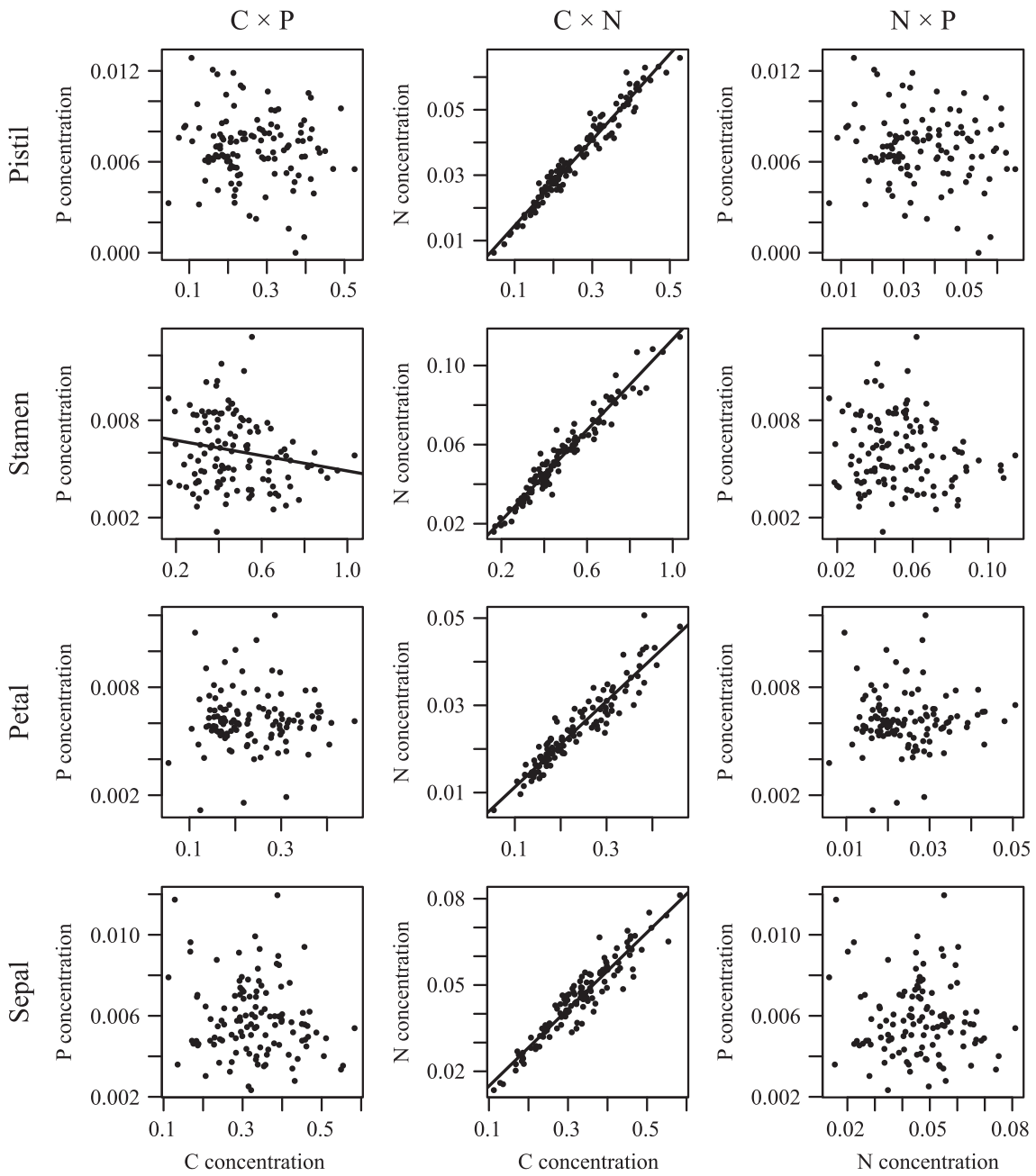

Figure 2 Bivariate correlations between the concentrations of carbon, nitrogen and phosphorous within each floral whorl from plants growing in the control treatment (well-watered/non-competitive). Presence of a best-fit line indicates a significant correlation.

Table 3 Selection gradients $(\beta)$ using male and female fitness estimates regressed on biomass and $\mathrm{N}$ content of floral whorls

\begin{tabular}{lccccc}
\hline \multirow{2}{*}{ Trait } & \multicolumn{2}{c}{$\begin{array}{c}\text { Relative total seed } \\
\text { production }\end{array}$} & & \multicolumn{2}{c}{$\begin{array}{c}\text { Relative total viable pollen } \\
\text { production }\end{array}$} \\
\cline { 2 - 3 } \cline { 5 - 6 } & $\beta \pm S E$ & F-value & & $\beta \pm S E$ & F-value \\
\hline Biomass & $0.54 \pm 0.055$ & $96.24^{* * * *}$ & & $0.54 \pm 0.040$ & $96.30^{* * * *}$ \\
Pistil N content & $0.14 \pm 0.063$ & $4.80^{*}$ & & $0.01 \pm 0.053$ & 0.02 \\
Stamen N content & $0.23 \pm 0.060$ & $15.00^{* * *}$ & & $0.13 \pm 0.059$ & $4.67^{*}$ \\
Petal N content & $-0.13 \pm 0.064$ & $3.85^{*}$ & & $0.04 \pm 0.057$ & 0.55 \\
Sepal N content & $-0.11 \pm 0.059$ & $3.13^{\dagger}$ & & $-0.14 \pm 0.060$ & $5.54^{*}$ \\
\hline
\end{tabular}

$\dagger P<0.08 ; * P<0.05 ; * * P<0.01 ; * * * P<0.001 ; * * * * P<0.0001$.

Traits were standardized to a mean of zero and standard deviation of one.

example, stamens) in combination with decreased allocation to other whorls (for example, sepals).

\section{QTL mapping and candidate gene analyses}

We mapped components of female (average seed per fruit and total seed set) and male fitness (average viable pollen per flower and total viable pollen production), organ mass, and CNP content, concentration and proportion in each organ. Given the refined mapping resolution of a recent high-density linkage map (Markelz et al., 2017) and large number of traits, we mapped a total of 200 QTL. Individual QTL explained 9.3\% (range: 4-23\%) of the genetic variance on average. In sum, all QTL for a given trait account for 39.7\% (range of total percent variance explained: $6.8-82.5 \%$ ) of the total genetic variance on average. A subset of the QTL results is displayed in Figure 3; complete results are presented in Supplementary Information, Supplementary Figure S3 and Supplementary Table S1. Included in the supporting QTL results (Supplementary Table S1) are the approximate location in $\mathrm{cM}, 2$-LOD limits, percent variance explained and additive effect.

We mapped numerous genomic regions affecting floral and fitness traits, most of which affected multiple floral traits and a mixture of both male and female whorls. The majority of mapped QTL across all traits (131 of 200 total QTL) showed positive additive effects, that is, the allele from the R500 parent increased the trait value. R500, for instance, contributed 8 out of 10 and 8 out of 11 positive effect alleles for $\mathrm{C}$ and $\mathrm{N}$ concentration, respectively. Interestingly, despite its smaller floral and vegetative size, IMB211 contributed the majority of alleles with positive effects on floral whorl phosphorus concentration (11 out of 12 QTL), a result at the QTL level that matches the lack of consistent genotypic associations between floral organ mass and $\mathrm{P}$ concentration. 

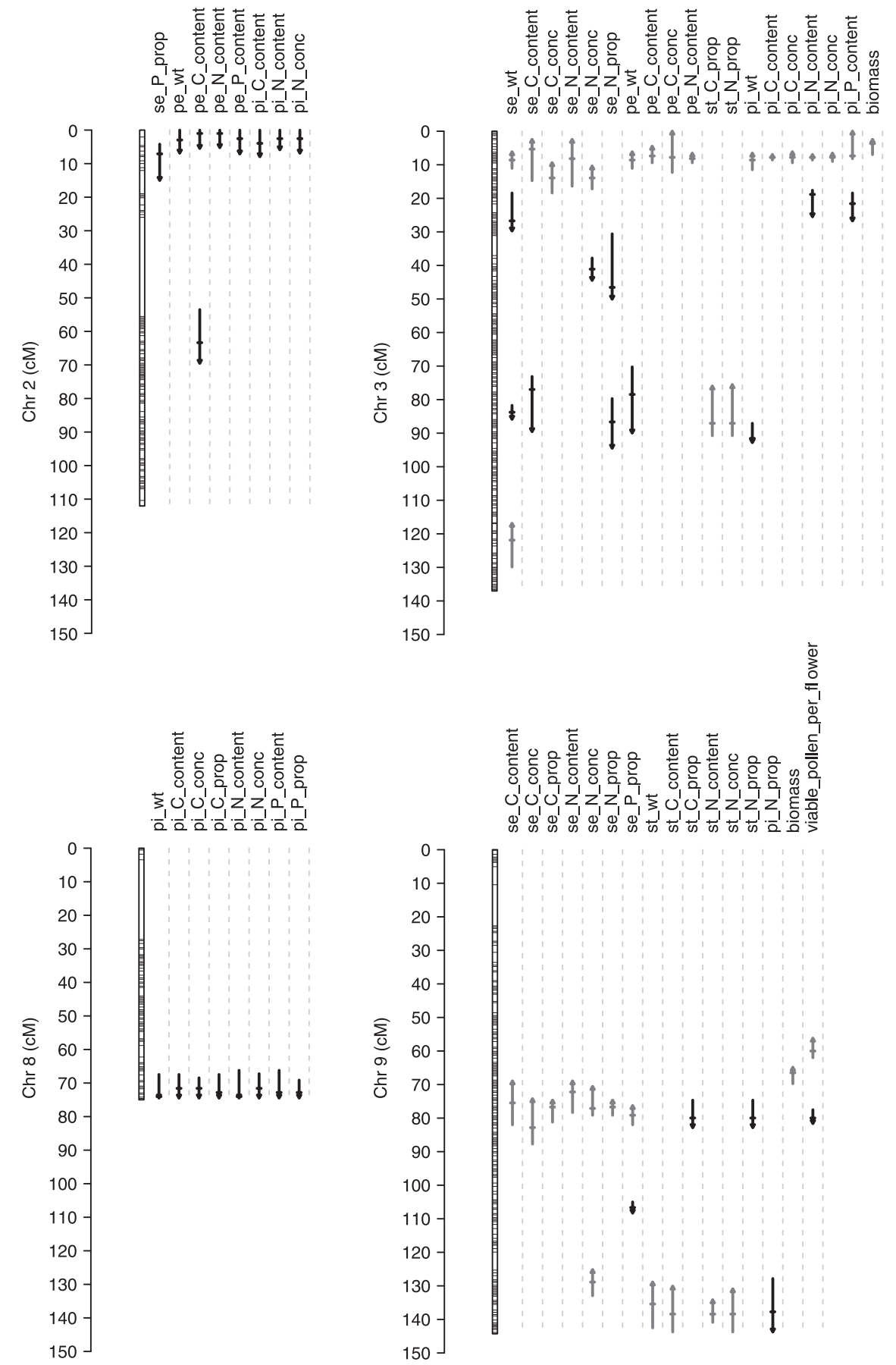

Figure 3 A subset of representative chromosomes and QTL are shown here to highlight the genetic architecture of floral allocation and fitness traits detected in a segregating progeny of $B$. rapa raised in the AES fields at the University of Wyoming. Vertical colored lines designate QTL with 2-LOD support limits, narrow horizontal lines illustrate QTL peaks and colored arrows denote directionality of additive effects of R500 alleles on trait means. Complete QTL results are presented in Supplementary information Table S1 and Supplementary Figure S3. A full color version of this figure is available at the Heredity journal online.

Many genomic locations were identified that contribute to the strongly positive genotypic correlations observed between $\mathrm{C}, \mathrm{N}$ and $\mathrm{P}$ (as estimated using content or concentration; Figure 3; Supplementary Information, Supplementary Figure S3). For instance, 11 QTL regions positively regulate allocation of one or more currencies to multiple floral whorls, including for example QTL at the top of A02 ( 5 cM) and A03 $(\sim 10 \mathrm{cM})$ that affect allocation to pistils, petals and sepals (Figure 3; Supplementary Information, Supplementary Figure S3,
Supplementary Table S1 and Table S1 footnote 1). Of these 11 QTL, 4 affect $\mathrm{C}, \mathrm{N}$ or $\mathrm{P}$ allocation independent of mass (Supplementary Information, Supplementary Figure S3, Supplementary Table S1 and Table S1 footnote 1). In 17 cases, QTL have similar effects on allocation of multiple currencies $(\mathrm{CNP})$ to a single whorl (Supplementary Information, Supplementary Figure S3, Supplementary Table S1 and Table S1 footnote 2); for instance, a QTL near the bottom of A08 $(\sim 75 \mathrm{cM})$ affects pistil CNP (Figure 3), 
suggesting such QTL enhance allocation in a whorl-specific manner. Ten QTL suggested tradeoffs involving different metrics (content, concentration or proportion) of allocation to floral whorls (Supplementary Information, Supplementary Figure S3, Supplementary Table S1 and Table S1 footnote 3); for instance, QTL on A03 ( $~ 85 \mathrm{cM})$ and A09 $(\sim 80 \mathrm{cM})$ have opposing effects on stamen vs sepal $\mathrm{N}$ and $\mathrm{C}$ (Figure 3 ).

Sixteen QTL were identified that contributed to male or female floral performance and selection on allocation (Supplementary Information, Supplementary Figure S3, Supplementary Table S1 and Table S1 footnote 4$)$; for instance, on A09 $(\sim 80 \mathrm{cM})$, a QTL with negative effects on male performance at the flower level and on stamen proportional $\mathrm{N}$ and $\mathrm{C}$ allocation carried positive effects for multiple metrics of sepal CNP allocation (Figure 3), consistent with genotypic selection through a component of male function.

Based on size (narrowness) of the 2-LOD support limits and circumscribed function (affecting allocation to only one whorl), we selected two QTL regions to explore for possible causal genes: (1) at the bottom of A08 that is specific to pistil mass and CNP allocation and (2) at the bottom of A09 that is predominantly related to stamen mass and $\mathrm{CN}$ allocation. The peak of the pistil allocation QTL on A08 (Figure 3) is eight genes removed from a homolog of the Arabidopsis shoot meristem gene, FANTASTIC FOUR 2 (FAF2; At1g03170), which has been shown to influence meristem size, and, in comparison with remaining whorls, FAF2 is highly expressed in Arabidopsis pistils. The stamen CN allocation QTL peak (bottom of A09; Figure 3) is physically proximate to a homolog of an Arabidopsis nitrate transporter (AtNRT2.1; Atlg08090), which is highly expressed in not only roots but also in pollen.

\section{DISCUSSION}

In cosexual species, fitness may be maximized by differential allocation to male vs female reproductive function (Charlesworth and Charlesworth, 1981; Brunet, 1992; Torices and Mendez, 2014). Yet, estimated allocation may vary depending on currency choice (Harper, 1977; Lovett Doust and Harper, 1980; Chapin, 1989; Ashman, 1994a, 1994b) and on environmental conditions as well as the relative sensitivity of different floral whorls to the environment. As a consequence of varying allocation estimates, the genetic architecture of and possible constraints on adaptive allocation strategies remain unclear. Here, we examined allocation patterns in a hermaphroditic species under multiple environmental conditions commonly encountered by wild and cultivated populations of the species. Allocation was environmentally sensitive, and whorls that serve male vs female function responded differently to stress imposed by drought vs competition. Further, the allocation response of one currency to environmental stress (for example, pistil C) did not reflect that of a second currency (for example, pistil P; cf. Table 2), indicating that measures of one currency are insufficient to understand all floral allocation responses to the environment. Likewise, at the genotypic level, while mass and content of all currencies were strongly positively correlated, mass did not correlate consistently with currency concentration (that is, $\mathrm{P}$ concentration) within whorls. Between whorls, content or concentration of any currency was typically positively correlated (for example, pistil $\mathrm{N}$ content or concentration was positively correlated with stamen, petal and sepal $\mathrm{N}$ at the genotypic and QTL levels). With regard to selection, significant genotypic selection was observed on nutrient content or concentration allocated to the floral whorls, in which selection favored an increase in allocation to some whorls and a decrease in allocation to other whorls; thus, the positive correlations in allocation are antagonistic to the joint vector of selection. At the QTL level, the vegetatively smaller parent (IMB211) contributed far fewer positive effect alleles for $\mathrm{N}$ and C allocation than the second parent (R500), but donated nearly all of the positive effect alleles for $\mathrm{P}$ allocation. Several positional candidate genes with whorl-specific effects emerge from QTL mapping.

\section{Environmental sensitivity of floral nutrient allocation}

Both plant density and moisture are distributed coarsely over the landscape, and heterogeneity in these two environmental features may affect not only carbon pools but also the ability to take up $\mathrm{N}$ and $\mathrm{P}$ from the environment (Schlesinger et al., 1996; Wang et al., 2009). Allocation of biomass to floral organs is sensitive to competition and moisture (Carroll et al., 2001; Dykstra et al., 2009; Table 2; Lambrecht and Dawson, 2007). In the current study, both competition and drought reduced allocation of CNP in all organs at the level of the whole-plant reproductive budget. At the level of the flower, the detrimental effects of stressful competitive vs drought treatments varied among whorls. The difference between the plant- and flowerlevel likely arises from large genotypic differences in size and total flower number (28-fold differences among RILs), which outweighs smaller differences in within-flower allocation patterns (twofold differences among RILs; Carroll and Delph, 1996). After statistically accounting for genotypic variation in size, we nevertheless observe significant selection on flower-level allocation, indicating that this level of allocation is relevant to male and female reproductive output. Moreover, while plants may experience unavoidable reductions in total flower number when stressed, active flower-level nutrient (re)allocation may be one mechanism to adaptively buffer fitness.

With regard to flower-level allocation patterns, total $\mathrm{N}$ in flowers was lower in both the competition and drought treatments relative to the control. Nitrogen (as well as mass and C) allocation to female structures (pistils and sepals) decreased in response to competition, while $\mathrm{N}$ allocation to the male structures (stamens) was negatively affected by drought. For these currencies, the results suggest that in the hermaphrodite $B$. rapa female allocation may be more detrimentally affected by plant competition whereas male allocation will be more negatively impacted by low moisture. For $\mathrm{N}$, the differential allocation to female vs male whorls across environments also suggests a physiological tradeoff, in which a reduction in total $\mathrm{N}$ elicits environment-specific preferential allocation to one function over the other (for example, while pistil and sepal allocation decreases under competition, stamen allocation shows homeostasis under this environmental stress). Pistil $\mathrm{P}$ showed different patterns of environmental response relative to pistil $\mathrm{C}$ and $\mathrm{N}$, namely being unaffected by competition but experiencing a $\sim 50 \%$ reduction in drought (Table 2 ); stamen $\mathrm{P}$ was unaffected by either treatment. The contrasting responses patterns of $\mathrm{C}, \mathrm{N}$ and mass vs $\mathrm{P}$ indicate that the detrimental effects of environmental stress on reproductive allocation to floral whorls are not uniform among currencies. In sexually dimorphic species, males commonly inhabit xeric sites and exhibit greater physiological adaptation to dry sites than females (Dawson and Ehleringer, 1993; Dudley, 2006; but see Dawson and Geber, 1999). In cosexual species, it would be interesting to further test correlations between gas exchange, performance and relative 'maleness' of a genotype, as estimated by pollen/ovule production or proportional allocation to stamens and petals vs pistil and sepals.

Genetic variation in allocation to male vs female whorls within one environment and choice of allocation currencies

Independent of environment, species may exhibit intraspecific variation in allocation patterns. In hermaphrodites of the gynodioecious 
species, Sidalcea oregana, sepals and the gynoecia consume a greater amount of the $\mathrm{N}$ relative to biomass budget, while pollen and the gynoecia consume a disproportionate share of the $\mathrm{P}$ relative to biomass budget (Ashman and Baker, 1992). In the cosexual species, Paeonia cambessedesii, stamens and gynoecia consumed a disproportionate amount of the $\mathrm{N}$ and $\mathrm{P}$ relative to biomass budgets (Mendez and Traveset, 2003). Thus, inferring relative allocation from biomass in these species would underestimate investment in some floral organs while overestimating investment in others. In the current study, allocation differed among floral whorls, such that mass and content of each of $\mathrm{C}, \mathrm{N}$ and $\mathrm{P}$ was highest to stamens followed by sepals, pistils and petals (Figure 1; Supplementary Information, Supplementary Figure S2); correspondingly, mass was positively correlated with C, $\mathrm{N}$ and $\mathrm{P}$ contents within a floral whorl. Depending on species, biomass may or may not relate to allocation of other currencies, and further studies are needed to understand how commonly cosexual species invest nutrients differentially in (and achieve greater fitness via) male vs female function.

From an evolutionary perspective, it is worth specifically considering not only content but also concentration and proportional allocation, because these two estimates provide a relative measure of allocation that is tied directly to biochemical activity (for example, $\mathrm{N}$ concentration and carbon assimilation; Reich et al., 1997); any observed fitness effects therefore reflect the return on relative investment of a finite resource that might otherwise be allocated elsewhere (Brunet, 1992). Inferring from the allocation of absolute amounts of biomass, $\mathrm{N}$, and $\mathrm{P}$ in replicate individuals, concentrations of one currency did not predict a second currency in hermaphrodites of a sexually dimorphic species (Sidalcea oregana) or in a cosexual species (Paeonia cambessedesii) (Ashman and Baker, 1992; Mendez and Traveset, 2003), which is unsurprising given the lack of correlation among contents in those studies. Genotypic correlations among currency concentrations were likewise more variable than for content in the current study. The correlation between mass and P concentration was either non-significant (petals, stamens) or negative (sepals, pistils). Further, carbon concentrations were strongly positively correlated with nitrogen concentrations in all organs, but $\mathrm{C}$ and $\mathrm{N}$ were generally uncorrelated with $\mathrm{P}$ concentration (Figure 2). Thus, as for environmental effects, genotypic nutrient concentrations cannot be reliably inferred from biomass and must be ascertained directly.

The relevant currency to estimate reproductive allocation has been heavily debated; biomass may be appropriate because it predicts energy allocation (Hickman and Pitelka, 1975; Abrahamson and Caswell, 1982; Reekie and Bazzaz, 1987a, b) or the limiting mineral nutrient may be most appropriate (Harper, 1977; Thompson and Stewart, 1981; Chapin, 1989). Given the variable associations observed here and elsewhere between mass and nutrient currencies as well as among currencies, one efficient empirical approach could be to estimate mass and nutrient limitation via Timmer vector analyses (Timmer and Stone, 1978). Specifically, a Timmer vector analysis quantifies the growth effects of content and concentration of diverse currencies simultaneously, thereby identifying the nutrient(s) that are limiting to growth and eventual performance. In the context of understanding resource allocation strategies and tradeoffs, the results of a Timmer vector analysis would enable researchers to hone in on and measure only the most relevant (limiting) currencies.

\section{Genotypic selection and evolutionary constraints on allocation}

Reproductive allocation that improves fitness through one function is commonly expected to come at the cost of another function, given finite resource pools (Stearns, 1992). In angiosperms, there is evidence of physiological allocation tradeoffs between male and female function. In the hermaphroditic species, Nigella sativa, stamen removal leads to heavier seeds (higher allocation to female function), while style removal and attendant reductions in fruit production lead to a $57 \%$ increase in biomass allocated to the stamens (higher allocation to male function) (Andersson, 2003). Here, we observed positive associations among measures of currency content and concentration at both the genotypic and QTL levels (Figure 3). Positive correlations may arise when genotypes differ in resource acquisition, because small genotypes show lower allocation to all functions in comparison to large genotypes and the population as a whole therefore expresses positive correlations among competing functions (Haselhorst et al., 2011). Consistent with this hypothesis, the RILs used here differ in gas-exchange levels and C fixation (Edwards et al., 2009, 2011, 2016), which may have also affected $\mathrm{N}$ acquisition.

With regard to evolutionary potential, genetic correlations are most informative when examined in light of selection (Etterson and Shaw, 2001). We examined selection acting through either male or female function on allocation, as estimated by content or concentration (but not proportion because the trait values for the 4 whorls must sum to 1 and are therefore strongly related, leading to multicollinearity in regression). After statistically accounting for differences in plant size, male fitness increased in plants with greater allocation to stamens and lower allocation to sepals, while female fitness was enhanced in plants with higher allocation to both stamens and pistils and lower allocation to sepal and petal whorls. Given the self-compatible (SC) breeding system in this population, genotypes that invested in floral display (petals) may have experienced structural costs or perianth water loss (Galen et al., 1999; Galen, 2000; Teixido and Valladares, 2013) without deriving significant fitness gain from enhanced pollinator visitation (Stanton et al., 1986). Correspondingly, SC apetalous canola mutants (B. napus) have greater non-petal whorl biomass (Jiang, 2007), suggesting costs associated with petals. However, negative pleiotropic effects of apetalous mutants on pollen production may limit the utility of these mutations in yield improvement in canola (Jiang and Becker, 2001). Breeding programs drawing on natural alleles in SC canola populations (B. rapa and B. napus) might enhance yield by selecting for rare recombinant genotypes that fall away from the primary axis of positive trait covariation toward floral phenotypes with reduced allocation to accessory perianth whorls in combination with increased allocation to the primary whorls.

\section{QTL mapping and candidate genes for whorl-specific allocation}

QTL mapping reveals unanticipated differences between the parents in allocation. At maturity, IMB211 is smaller than R500, both with regard to size of floral organs and vegetative biomass (Brock et al., 2010; Haselhorst et al., 2011). IMB211 also has lower leaf $\mathrm{N}$ accumulation and lower gas-exchange rates (Edwards et al., 2011, 2012). IMB211 correspondingly contributes the majority of alleles with negative additive effects for all traits measured here and in previous studies. However, the IMB211 parent contributes the majority of alleles with positive additive effects on $\mathrm{P}$ concentration in floral organs. $\mathrm{N}$ is primarily associated with proteins, while $\mathrm{P}$ is associated with both cell energetics and transfer and expression of hereditary information (Niklas et al., 2005); P demand and selection for P acquisition might be higher in IMB211 due to high cell-cycle activity associated with its short lifespan and rapid growth, which increases P demand (Lai et al., 2007). Whether the positive additive effects of $P$ concentration alleles from IMB211 derive from more efficient allocation or uptake will require further experimentation. Regardless of the future findings, 
agricultural fertilizers are expensive and base nutrients, like $\mathrm{P}$, are predicted to be scarcer in the future (Cordell et al., 2009; Gilbert, 2009); inclusion of these alleles in breeding experiments may lead to more efficient nutrient use in crops.

This experimental RIL population, with numerous generations of recombination resolved by dense marker coverage, enabled the detection of QTL that range in effect from those that influence numerous whorls and currencies (for example, top of A03), to those that are more currency- or trait-specific (for example, bottom of A08). Examination of genome annotations in the physical regions defined by QTL boundaries reveals several strong candidates. First, a homolog of the Arabidopsis Fantastic Four 2 gene (FAF2) is adjacent to the QTL peak on the bottom of chromosome eight, a QTL that regulates mass and CNP allocation solely in the pistil whorl (Figure 3). FAF2 shows high expression restricted to the pistil in late-stages of Arabidopsis floral development (Wahl et al., 2010). Moreover, FAF2 functions in the shoot/floral meristem regulatory network partially governed by WUSCHEL (WUS; Laux et al., 1996) and CLAVATA 3 (CLV3; Clark et al., 1996), which together establish a negative feedback loop influencing stem cell identity and their population size in the meristem (Schoof et al., 2000). Second, the 1-LOD QTL region at the bottom of A09 (Figure 3), which influences $\mathrm{N}$ allocation to the stamen, contains a gene homologous to the Arabidopsis Nitrate Transporter 2.1 (NRT2.1; Filleur and Daniel-Vedele, 1999; Zhuo et al., 1999). In Arabidopsis, NRT2.1 is involved in the high-affinity nitrate transport system that acts under low external nitrate concentrations and is expressed in pollen (Schmid et al., 2005). In our population, variation in $\mathrm{N}$ acquisition via possible allelic variation at NRT2.1 may disproportionately influence stamens, which have the highest $\mathrm{N}$ content of all floral whorls (Figure 1). While the narrow QTL regions housing relevant, annotated genes suggest strong candidates, additional fine-scale mapping, gene expression or gene-editing experiments would be necessary to confirm a causal role of these genes in regulating floral allocation.

\section{DATA ARCHIVING}

Raw data files of floral nutrients and organ mass are archived in DRYAD (doi:10.5061/dryad.5m6p3). Genetic map files are archived in DRYAD (doi: 10.5061/dryad.cj375).

\section{CONFLICT OF INTEREST}

The authors declare no conflict of interest.

\section{ACKNOWLEDGEMENTS}

We thank K. Belden and the UW Stable Isotope Facility for advice on nutrient assays. We also thank three anonymous reviewers for their insightful comments. This research was funded by NSF grants IOS-0923752 to CW and IOS-1025965 to CW and BEE.

Abrahamson WG, Caswell H (1982). On the comparative allocations of biomass, energy, and nutrients in plants. Ecology 63: 982-991.

Adler L, Wikler K, Wyndham F, Linder C, Schmitt J (1993). Potential for persistence of genes escaped from canola: germination cues in crop, wild, and crop-wild hybrid Brassica rapa. Funct Ecol 7: 736-745.

Andersson S (2003). Sex-allocation trade-offs in Nigella sativa (Ranunculaceae) examined with flower manipulation experiments. Evol Ecol 17: 125-138.

Ashman TL (1994a). A dynamic perspective on the physiological cost of reproduction in plants. Am Nat 144: 300-316.

Ashman TL (1994b). Reproductive allocation in hermaphrodite and female plants of Sidalcea oregana ssp. spicata (Malvaceae) using four currencies. Am J Bot 81: 433-438.
Ashman TL, Baker I (1992). Variation in floral sex allocation with time of season and currency. Ecology 73: 1237-1243.

Bazzaz F, Carlson R, Harper J (1979). Contribution to reproductive effort by photosynthesis of flowers and fruits. Nature 279: 554-555.

Bell G (1985). On the function of flowers. Proc R Soc Lond Ser B Biol Sci 224: 223-265.

Brock MT, Dechaine JM, Iniguez-Luy FL, Maloof JN, Stinchcombe JR, Weinig C (2010). Floral genetic architecture: an examination of QTL architecture underlying floral (co) variation across environments. Genetics 186: 1451-1465.

Brock MT, Lucas LK, Anderson NA, Rubin MJ, Markelz RJC, Covington MF et al. (2016). Genetic architecture, biochemical underpinnings, and ecological impact of floral UV patterning. Mol Ecol 25: 1122-1140.

Brunet J (1992). Sex allocation in hermaphroditic plants. Trends Ecol Evol 7: 79-84.

Campbell DR (1997). Genetic correlation between biomass allocation to male and female functions in a natural population of Ipomopsis aggregata. Heredity 79: 606-614.

Carroll AB, Pallardy SG, Galen C (2001). Drought stress, plant water status, and floral trait expression in fireweed, Epilobium angustifolium (Onagraceae). Am J Bot 88: 438-446.

Carroll SB, Delph LF (1996). The effects of gender and plant architecture on allocation to flowers in dioecious Silene latifolia (Caryophyllaceae). Int J Plant Sci 157: 493-500.

Chapin F (1989). The cost of tundra plant structures: evaluation of concepts and currencies. Am Nat 133: 1-19.

Charlesworth D, Charlesworth B (1981). Allocation of resources to male and female functions in hermaphrodites. Biol J Linn Soc 15: 57-74.

Chen PS, Toribara TY, Warner H (1956). Microdetermination of phosphorus. Anal Chem 28: 1756-1758.

Clark SE, Jacobsen SE, Levin JZ, Meyerowitz EM (1996). The CLAVATA and SHOOT MERISTEMLESS loci competitively regulate meristem activity in Arabidopsis. Development 122: 1567-1575.

Conner J, Via S (1993). Patterns of phenotypic and genetic correlations among morphological and life-history traits in wild radish, Raphanus raphanistrum. Evolution 47: 704-711.

Cordell D, Drangert JO, White S (2009). The story of phosphorus: global food security and food for thought. Glob Environ Change 19: 292-305.

Dawson TE, Ehleringer JR (1993). Gender-specific physiology, carbon isotope discrimination, and habitat distribution in boxelder, Acer negundo. Ecology 74: 798-815.

Dawson TE, Geber MA (1999). Sexual dimorphism in physiology and morphology. In: Geber MA, Dawson TE, Delph LF (eds). Gender And Sexual Dimorphism In Flowering Plants. Springer: New York. pp 175-215.

de Craene LPR (2003). The evolutionary significance of homeosis in flowers: a morphological perspective. Int J Plant Sci 164: 225-235.

Diggle PK (1997). Ontogenetic contingency and floral morphology - the effects of architecture and resource limitation. Int J Plant Sci 158 (6 Suppl S): S99-S107.

Dorken ME, Barrett SC (2004). Phenotypic plasticity of vegetative and reproductive traits in monoecious and dioecious populations of Sagittaria latifolia (Alismataceae): a clonal aquatic plant. J Ecol 92: 32-44.

Dudley LS (2006). Ecological correlates of secondary sexual dimorphism in Salix glauca (Salicaceae). Am J Bot 93: 1775-1783.

Dykstra AB, Brock MT, Delph LF, Weinig C (2009). Sex specific trade-offs and responses to foliar shade in the gynodioecious species Silene vulgaris (Caryophyllaceae). Int J Plant Sci 170: 575-583.

Edwards CE, Ewers BE, McClung CR, Lou P, Weinig C (2012). Quantitative variation in water-use efficiency across water regimes and its relationship with circadian, vegetative, reproductive, and leaf gas-exchange traits. Mol Plant 5: 127-142.

Edwards CE, Ewers BE, Weinig C (2016). Genotypic variation in biomass allocation in response to field drought has a greater affect on yield than gas exchange or phenology. BMC Plant Biol 16: 185.

Edwards CE, Ewers BE, Williams DG, Xie Q, Lou P, Xu X et al. (2011). The genetic architecture of ecophysiological and circadian traits in Brassica rapa. Genetics 189: 375-390.

Edwards CE, Haselhorst MSH, McKnite AM, Ewers BE, Williams DG, Weinig C (2009). Genotypes of Brassica rapa respond differently to plant-induced variation in air $\mathrm{CO} 2$ concentration in growth chambers with standard and enhanced venting. Theor Appl Genet 119: 991-1004.

Etterson JR, Shaw RG (2001). Constraint to adaptive evolution in response to global warming. Science 294: 151-154.

Filleur S, Daniel-Vedele F (1999). Expression analysis of a high-affinity nitrate transporter isolated from Arabidopsis thaliana by differential display. Planta 207: 461-469.

Fineblum WL, Rausher MD (1995). Tradeoff between resistance and tolerance to herbivore damage in a morning glory. Nature 377: 517-520.

Flexas J, Bota J, Loreto F, Cornic G, Sharkey T (2004). Diffusive and metabolic limitations to photosynthesis under drought and salinity in C3 plants. Plant Biol 6: 269-279.

Galen C (1989). Measuring pollinator-mediated selection on morphometric floral traits: bumblebees and the alpine sky pilot, Polemonium viscosum. Evolution 43: 882-890.

Galen C (2000). High and dry: drought stress, sex-allocation trade-offs, and selection on flower size in the alpine wildflower Polemonium viscosum (Polemoniaceae). Am Nat 156: 72-83.

Galen C, Sherry RA, Carroll AB (1999). Are flowers physiological sinks or faucets? Costs and correlates of water use by flowers of Polemonium viscosum. Oecol 118: 461-470.

Geber MA (1990). The cost of meristem limitation in Polygonum arenastrum: negative genetic correlations between fecundity and growth. Evolution 44: 799-819.

Gilbert N (2009). Environment: the disappearing nutrient. Nature 461: 716-718.

Harper JL (1977). Population Biology Of Plants. Academic Press: London.

Haselhorst MSH, Edwards CE, Rubin MJ, Weinig C (2011). Genetic architecture of life history traits and environment specific trade offs. Mol Ecol 20: 4042-4058. 
Havens K, Preston KA, Richardson C, Delph LF (1995). Nutrients affect allocation to male and female function in Abutilon theophrasti (Malvaceae). Am J Bot 82: 726-733.

Hickman JC, Pitelka LF (1975). Dry weight indicates energy allocation in ecological strategy analysis of plants. Oecol 21: 117-121.

Hinata K, Prakash S (1984). Ethnobotany and evolutionary origin of Indian Oleiferous Brassicae. Indian J Genet Plant Breed 44: 102-112.

Iniguez-Luy FL, Lukens L, Farnham MW, Amasino RM, Osborn TC (2009). Development of public immortal mapping populations, molecular markers and linkage maps for rapid cycling Brassica rapa and B. oleracea. Theor App/ Genet 120: 31-43.

Jiang $L$ (2007). Breeding for apetalous rape: inheritance and yield physiology. Adv Bot Res 45: 217-231.

Jiang L, Becker HC (2001). Environmental effects on expression of apetalous flowers in oilseed rape. J Appl Bot-Angew Bot 75: 75-79.

Juenger T, Pérez-Pérez JM, Bernal S, Micol JL (2005). Quantitative trait loci mapping of floral and leaf morphology traits in Arabidopsis thaliana: evidence for modular genetic architecture. Evol Dev 7: 259-271.

Lai F, Thacker J, Li YY, Doerner P (2007). Cell division activity determines the magnitude of phosphate starvation responses in Arabidopsis. Plant J 50: 545-556.

Lambrecht SC, Dawson TE (2007). Correlated variation of floral and leaf traits along a moisture availability gradient. Oecol 151: 574-583.

Lande R, Arnold SJ (1983). The measurement of selection on correlated characters. Evolution 37: 1210-1226

Laporte MM, Delph LF (1996). Sex-specific physiology and source-sink relations in the dioecious plant Silene latifolia. Oecol 106: 63-72.

Latta RG, Gardner KM (2009). Natural selection on pleiotropic quantitative trait loci affecting a life-history trade-off in Avena barbata. Evolution 63: 2153-2163.

Laux T, Mayer KFX, Berger J, Jurgens G (1996). The WUSCHEL gene is required for shoot and floral meristem integrity in Arabidopsis. Development 122: 87-96.

Leimu R, Koricheva J (2006). A meta-analysis of tradeoffs between plant tolerance and resistance to herbivores: combining the evidence from ecological and agricultural studies. Oikos 112: 1-9.

Li P, Huang B, Pemberton R, Luo Y, Cheng J (2011). Floral display influences male and female reproductive success of the deceptive orchid Phaius delavayi. Plant Syst Evol 296: 21-27.

Linder S (1987). Canopy dynamics and growth of Pinus radiata: I. Effects of irrigation and fertilization during a drought. Can J For Res 17: 1157-1165.

Lloyd DG (1984)Gender allocations in outcrossing cosexual plantsIn:Dirzo R, Sarukhan J (eds) Perspectives On Plant Population Ecology. Sinauer: Sunderland, Massachesetts, USA. pp 277-300.

Lloyd DG, Bawa KS (1984). Modification of the gender of seed plants in varying conditions. Evol Biol 17: 255-338.

Lovett Doust J, Harper JL (1980). The resource costs of gender and maternal support in an andromonoecious Umbellifer, Smyrnium olusatrum L. New Phytol 85: 251-264.

Maliakal SK, McDonnell K, Dudley SA, Schmitt J (1999). Effects of red to far-red ratio and plant density on biomass allocation and gas exchange in Impatiens capensis. Int J Plant Sci 160: 723-733.

Markelz RJC, Covington MF, Brock MT, Devisetty UK, Kliebenstein DJ, Weinig C et al. (2017). Using RNA-seq for genomic scaffold placement, correcting assemblies, and genetic map creation in a common Brassica rapa mapping population. G3 (Bethesda) 7: 2259-2270.

Mendez M, Traveset A (2003). Sexual allocation in single-flowered hermaphroditic individuals in relation to plant and flower size. Oecol 137: 69-75.

Niklas KJ, Owens T, Reich PB, Cobb ED (2005). Nitrogen/phosphorus leaf stoichiometry and the scaling of plant growth. Ecol Lett 8: 636-642.

Onillon B, Durand J-L, Gastal F, Tournebize R (1995). Drought effects on growth and carbon partitioning in a tall fescue sward grown at different rates of nitrogen fertilization. Eur J Agron 4: 91-99.

Osone Y, Ishida A, Tateno M (2008). Correlation between relative growth rate and specific leaf area requires associations of specific leaf area with nitrogen absorption rate of roots. New Phytol 179: 417-427.

Rausher MD (1992). The measurement of selection on quantitative traits: biases due to environmental covariances between traits and fitness. Evolution 46: 616-626.
Reekie E, Bazzaz F (1987a). Reproductive effort in plants. 1. Carbon allocation to reproduction. Am Nat 129: 876-896.

Reekie E, Bazzaz F (1987b). Reproductive effort in plants. 2. Does carbon reflect the allocation of other resources? Am Nat 129: 897-906.

Reich PB, Walters MB, Ellsworth DS (1997). From tropics to tundra: global convergence in plant functioning. Proc Natl Acad Sci USA 94: 13730-13734.

Rodriguez-Riano T, Dafni A (2000). A new procedure to asses pollen viability. Sex Plant Reprod 12: 241-244.

Roff D, Fairbairn D (2007). The evolution of trade-offs: where are we? J Evol Biol 20: 433-447.

Sakai AK, Weller SG, Campbell DR, Culley TM, Dunbar-Wallis AK, Andres AM (2013). Measure for measure: comparing morphological and biomass traits for sex allocation in two gynodioecious species. Am J Bot 100: 1071-1082.

Schlesinger WH, Raikes JA, Hartley AE, Cross AF (1996). On the spatial pattern of soil nutrients in desert ecosystems. Ecology 77: 364-374.

Schmid M, Davison TS, Henz SR, Pape UJ, Demar M, Vingron M et al. (2005). A gene expression map of Arabidopsis thaliana development. Nat Genet 37: 501-506.

Schoof H, Lenhard M, Haecker A, Mayer KFX, Jurgens G, Laux T (2000). The stem cell population of Arabidopsis shoot meristems is maintained by a regulatory loop between the CLAVATA and WUSCHEL genes. Cell 100: 635-644.

Schulze E (1986). Whole-plant responses to drought. Funct Plant Biol 13: 127-141.

Stanton ML, Snow AA, Handel SN (1986). Floral evolution: attractiveness to pollinators increases male fitness. Science 232: 1625-1627.

Stearns SC (1992). The Evolution Of Life Histories. Oxford University Press: Oxford.

Teixido AL, Valladares F (2013). Large and abundant flowers increase indirect costs of corollas: a study of coflowering sympatric Mediterranean species of contrasting flower size. Oecol 173: 73-81.

Thompson K, Stewart A (1981). The measurement and meaning of reproductive effort in plants. Am Nat 117: 205-211.

Timmer VR, Stone EL (1978). Comparative foliar analysis of young balsam fir fertilized with nitrogen, phosphorus, potassium, and lime. Soil Sci Soc Am J 42: 125-130.

Torices R, Mendez M (2014). Resource allocation to inflorescence components is highly integrated despite differences between allocation currencies and sites. Int J Plant Sci 175: 713-723.

van Noordwijk AJ, Dejong G (1986). Acquisition and allocation of resources: their influcence on variation in life history tactics. Am Nat 128: 137-142.

Vasek F, Weng V, Beaver R, Huszar C (1987). Effects of mineral nutrition on components of reproduction in Clarkia unguiculata. Aliso 11: 599-618.

Wahl V, Brand LH, Guo YL, Schmid M (2010). The FANTASTIC FOUR proteins influence shoot meristem size in Arabidopsis thaliana. BMC Plant Biol 10: 285.

Wang S, Basten CJ, Zeng Z-B (2007). Windows QTL Cartographer 2.5. Department of Statistics, North Carolina State University: Raleigh, NC. Available at: http://statgen. ncsu.edu/qtlcart/WQTLCart.htm.

Wang Y, Zhang X, Huang C (2009). Spatial variability of soil total nitrogen and soil total phosphorus under different land uses in a small watershed on the Loess Plateau, China. Geoderma 150: 141-149.

Weinig C (2000a). Plasticity versus canalization: Population differences in the timing of shade-avoidance responses. Evolution 54: 441-451.

Weinig C (2000b). Differing selection in alternative competitive environments: shadeavoidance responses and germination timing. Evolution 54: 124-136.

Welander NT, Ottosson B (2000). The influence of low light, drought and fertilization on transpiration and growth in young seedlings of Quercus robur L. Forest Ecol Manag 127: $139-151$.

Williams PH, Hill CB (1986). Rapid-cycling populations of Brassica. Science 232: 1385. Zhang YF, Zhang DQ, Yu HS, Lin BG, Fu Y, Hua SJ (2016). Floral Initiation in response to planting date reveals the key role of floral meristem differentiation prior to budding in canola (Brassica napus L.). Front Plant Sci 7: 1369.

Zhao J, Wang X, Deng B, Lou P, Wu J, Sun R et al. (2005). Genetic relationships within Brassica rapa as inferred from AFLP fingerprints. Theor Appl Genet 110: 1301-1314.

Zhuo DG, Okamoto M, Vidmar JJ, Glass ADM (1999). Regulation of a putative high-affinity nitrate transporter (Nrt2; 1At) in roots of Arabidopsis thaliana. Plant J 17: 563-568.

Supplementary Information accompanies this paper on Heredity website (http://www.nature.com/hdy) 